\title{
Rapid Destruction of Biorecalcitrant Micropollutants in Pharmaceutical Wastewater Using Temperature-Elevated, Wet Hydrogen-Peroxide Oxidation Processes
}

\author{
Jirawan Supabroob ${ }^{1}$, Wipavadee Sangadkit ${ }^{2}$, Kenneth W. Foster ${ }^{3}$, Nopphon Weeranoppanant ${ }^{4}$ and \\ Aluck Thipayarat ${ }^{2,5}$
}

\begin{abstract}
Temperature-elevated, wet hydrogen-peroxide oxidation (TWHPO) has been used to destroy micropollutants in pharmaceutical wastewater. The first washes of equipment used for the routine production of three drugs were collected. The equipment cleaning wastewater was analyzed for pollutants. Based on these this observations analysis three different wastewater models were formulated with the concentrations of components significantly higher than their observed maximum values. TWHPO was able to degrade the tested compounds in the wastewater models with different degrees of efficacy. Amoxicillin were among the most resistant compounds; however, they were oxidized to non-detectable levels as determined by HPLC in $5 \mathrm{~min}$ using $5 \% \mathrm{H} 2 \mathrm{O} 2$ at $120 \mathrm{oC}$. The high reaction temperature combined with $\mathrm{H} 2 \mathrm{O} 2$ was hypothesized to facilitate $\mathrm{OH}$ production and hence their fast degradation.
\end{abstract}

Index Terms - Pharmaceutical, Hydrogen peroxide, High temperature, Wet oxidation treatment, Wastewater treatment.

\section{INTRODUCTION}

THE Pollution from pharmaceutical related products is a widespread and under-regulated source of environmental problems (Guillermo Cuevas, 2011) and the potential impact of these residues on ecosystem has drawn a growing international concern (Pengxiao Liu et al., 2013). The presence of pharmaceutical and personal care products (PPCPs) has been increasingly detected in natural water reservoirs, such as rivers, streams, creeks, and lakes (Halling-Sorensen et al., 1998; Jones et al., 2001; Heberer, 2002; Kolpin et al., 2002; Calamari et al., 2003). These aquatic contaminants reservoirs are an emerging class of hazardous compounds that enter our waterways mainly through the discharge of wastewaters and effluents. The reported from U.S. Geological Survey, 80 percent of between

Jirawan Supabroob1, Department of Environmental Engineering, Faculty of Engineering, Burapha University, Chonburi 20131, Thailand

Wipavadee Sangadkit2, Department of Food Engineering, Faculty of Engineering, King Mongkut's University of Technology Thonburi, Bangkok 10140, Thailand

Kenneth W. Foster3, Department of Physics, Syracuse University, NY 13244-1130, USA.

Nopphon Weeranoppanant 4, Department of Chemical Engineering, Faculty of Engineering, Burapha University, Chonburi 20131, Thailand

Aluck Thipayarat 5, Office of Education, Faculty of Engineering, Burapha University, Chonburi 20131, Thailand.
1999-2000 were contaminated by antibiotics, hypertensive and cholesterol-lowering drugs, antidepressants, analgesics, steroids, caffeine, and reproductive hormones (Kolpin et al., 2003; Barber et al., 2006). Among other potential sources, these chemical pollutants can be originated from human usage and excretions, improper disposal of surplus-drugs in households, medical care, and therapeutic treatment of livestock or else directly discharged from production sites.

Although drugs are believed to be absorbed and metabolized by the humans or animals via a series of metabolic reactions, some fractions of the original substances may remain intact secreted with urine or feces. Apart from residual contaminants from industry and agriculture, the household discharges emit these two important classes of pharmaceuticals into raw sewage, sewage sludge or manure and eventually enter the natural water supply. There were reports that several antibiotics were found in human faeces during a regular treatment period and some of the excreted metabolites were able to be reversed to the original active drug (Berger K, Petersen B, Buening-Pfaue H., 1986; Hoverstad et al., 1986). Several categories of pharmaceutical contaminants found organic wastewater is of critical concerns due to their potencies at low concentrations as well as their persistence and bioaccumulative tendency in the water reservoirs. Due to their persistent and bioaccumulative natures in natural water reservoirs, two types of pharmaceuticals, including antimicrobials and endocrine disrupting chemicals (EDCs), deserve priority attention. The discharges of these pharmaceuticals can potentially inflict a broad spectrum of negative human health effects as well as create a wide array of serious environmental problems (Christenson, 2008).

Many attempts have done to study the extent of environmental appearance, transport, and ultimate fate of antimicrobials, after their intended use (National Research Council, 1999; Daughton et al.,1999; Jorgensen et al.,2000). The most investigated route of entry of these pharmaceuticals into the environment was that from municipal wastewater treatment plants (WWTP). Unchanged or slightly transformed active pharmaceutical ingredients (APIs) from human excretion have been shown to conjugate to polar molecules, such as glucuronide, and enter the WWTP, releasing the original API into the environment (Heberer, 2002). It has been estimated that up to half of the pharmaceutical wastewater produced 
worldwide is discharged into natural water reservoirs with little or no treatment (Enick and Moore, 2007). Unfortunately, many WWTPs still utilize conventional biological reactors (e.g, activated sludge) reported to have a limited capacity to cancel the bioactivities of pharmaceutical pollutants (Rivera-Utrilla et al., 2013; Gracia-Lor et al., 2012; Quintana et al., 2004; Ternes et al., 1998). It is necessary to develop more effective and efficient technologies to treat the effluents and remove biorecalcitrant pharmaceutical compounds before discharge into the environment (Shemer et al., 2005).

The biological and physiochemical treatment methods described previously have shown limited success for the treatment of pharmaceutical wastewater (Deegan et al., 2011). However, the development of advanced oxidation processes is showing higher removal rates. Advanced oxidation processes (AOPs) have offered an unprecedented oxidizing power to mineralize such compounds and been acknowledged as a promising technology for treating polluted sources of drinking water and pharmaceutical wastewater. The principle of the technology is hinged on the mass generation of powerful hydroxyl radicals to react and degrade biorecalcitrant pollutants (Ku et al., 1997). A chemical agent such as hydrogen peroxide, ozone, transition metals and metal oxides are required for AOPs. In addition, an energy source such as ultraviolet-visible radiation, electric current, gamma-radiation and ultrasound is required (Ikehata et al., 2006). AOPs are based on the production of free radicals, in particular the hydroxyl radical and facilitate the conversion of pollutants to less harmful and more biodegradable compounds. AOPs habitually include ozonation coupled with hydrogen peroxide and Ultraviolet (UV) irradiation. Fenton and $\mathrm{TiO}_{2}$ photocatalysis are also employed, like $\mathrm{UV} / \mathrm{H}_{2} \mathrm{O}_{2}, \mathrm{UV} / \mathrm{H}_{2} \mathrm{O}_{2} / \mathrm{Fe}^{2+}\left(\mathrm{Fe}^{3+}\right)$, and $\mathrm{UV} / \mathrm{TiO}_{2}$.

\section{MAterials AND MethodS}

\section{A. Reagents and materials}

Three antibiotics (i.e., amoxicillin, ceftriaxone, and meropenem were used to prepare wastewater formulation imitating the first wash from equipment cleaning process of a local pharmaceutical factory (Samutprakarn, Thailand). These active ingredients were available in the salt compounds with the purity (>97\%). They were representing PPCP micro pollutants for both generic and industrial wastewater commonly found from most pharmaceutical factories. These samples of pharmaceutical waste are spiked into deionized (DI) water to simulate wastewater models from production. Other chemicals and material used in this experiment for example hydrogen peroxide (50\%, Chemipan Corporation Co. Ltd., Bangkok, Thailand), activated carbon (VP Greentech Co., Ltd., Rayong, Thailand), methanol (I.C.P. Chemicals Co., Ltd., Bangkok, Thailand) and acetonitrile (Chemipan Corporation Co. Ltd., Bangkok, Thailand) were prepared. All other reagents were analytical grade and used as received.

\section{B. Experimental setup}

The wet oxidation treatment was performed on a lab-scale prototype as shown in Figure 1. The equipment setting contains the aluminum heating block $(500 \mathrm{~W})$, the aluminum pressure vessel, the stainless steel lid equipped a pressure gauge (-1-7 bars), a release valve (1/4" NPT ) and a type-K thermocouple, as well as the temperature controlling unit. The wastewater model containing spiked PPCP contaminant was prepared prior to the treatment (Figure 1). The sample volume was weighted $20 \mathrm{~g}$ and mixed with a predetermined concentration of hydrogen peroxide. The spiked sample and $\mathrm{H} 2 \mathrm{O} 2$ mixture was poured into the reactor vessel preheated at $90^{\circ} \mathrm{C}$. Flame from a blow torch was applied to the vessel to heat up the temperature of the mixture. Once the desired temperature was reached, the reactor was incubated at the preset temperature in the aluminum heating block. The temperature of the mixture was monitored using the inserted type-K thermocouple connected to an electronic temperature reader. At each sample interval, $5 \mathrm{~mL}$ sample were drawn from the reactor via the release valve for further analyses.

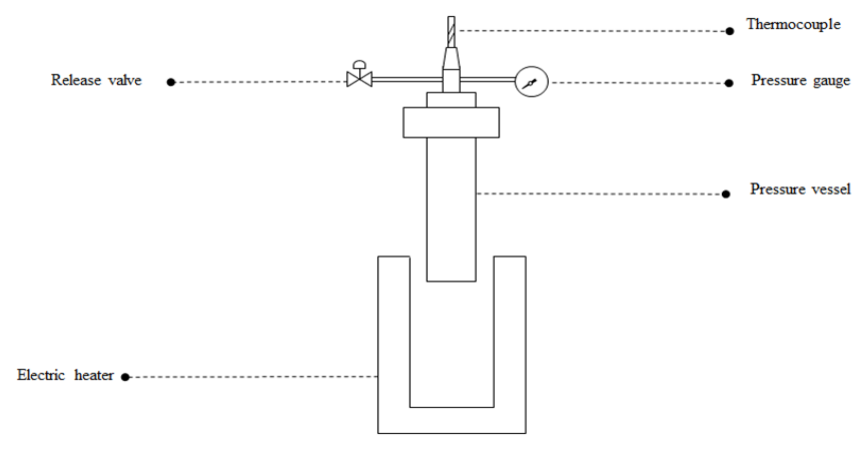

Fig. 1 Schematic iagram of the lab-scale reactor

\section{HPLC analysis of pharmaceutical residues after wet oxidation}

The concentration of pharmaceuticals was determined using an Agilent 1200 HPLC (Agilent, USA) using the following conditions:

Amoxicillin ( $4.0 \times 250 \mathrm{~mm} \mathrm{C18}$ column, mobile phase with acetonitrile: buffer ratio at $1: 24$, isocratic mode with a flow rate of $1.5 \mathrm{~mL}$ min-1, UV detector at UV $230 \mathrm{~nm}$ and injection volume at $10 \mu \mathrm{L})$.

Ceftriaxone $(4.6$ x $250 \mathrm{~mm} \mathrm{C18}$ column, mobile phase using $4 \mathrm{~g}$ of tetra-n-hepthylammonium bromide: $450 \mathrm{~mL}$ of acetonitrile: $490 \mathrm{~mL}$ of water:55 mL of buffer A :5 mL of buffer $\mathrm{B}$, isocratic mode with a flow rate of $1.6 \mathrm{~mL}$ min-1, UV detector at $254 \mathrm{~nm}$ and injection volume at $10 \mu \mathrm{L}$ ). Buffer $\mathrm{A}$ is $5.796 \mathrm{~g}$ of $\mathrm{NaHPO}_{4}$ anhydrous and $3.522 \mathrm{~g}$ of KH2PO4 and buffer B is $20.256 \mathrm{~g}$ citric acid mono and $7.840 \mathrm{~g} \mathrm{NaOH}$ in $1 \mathrm{~L}$ DI water.

Meropenem $(4.6 \mathrm{~mm} \times 250 \mathrm{~mm} \mathrm{C} 18$ reversed phase LC column with $5 \mu \mathrm{m}$ packing, mobile phase with acetonitrile: methanol: buffer at 150: 100: 750, isocratic mode with a flow rate of $1.5 \mathrm{~mL}$ min-1, UV detector at $300 \mathrm{~nm}$ and injection volume at $20 \mu \mathrm{L}$ ).

\section{Results And Discussions}

\section{A. Assessment of typical first wash from equipment cleaning}

These five environmentally relevant pharmaceuticals were chosen according to the routine production and local consumption from our collaborative pharmaceutical factories. 
The untreated and oxidatively treated wastewater characteristics of the first wash from equipment cleaning were analyzed by HPLC and COD titration. The HPLC analyses were performed at different batches of production. There were

a wide range of active ingredients present at each analysis of this local factory ranging from $0.50-1.8 \mathrm{mg} / \mathrm{mL}$ amoxicillin, 0.05-0.30 mg/mL ceftriaxone, (Fig.2)

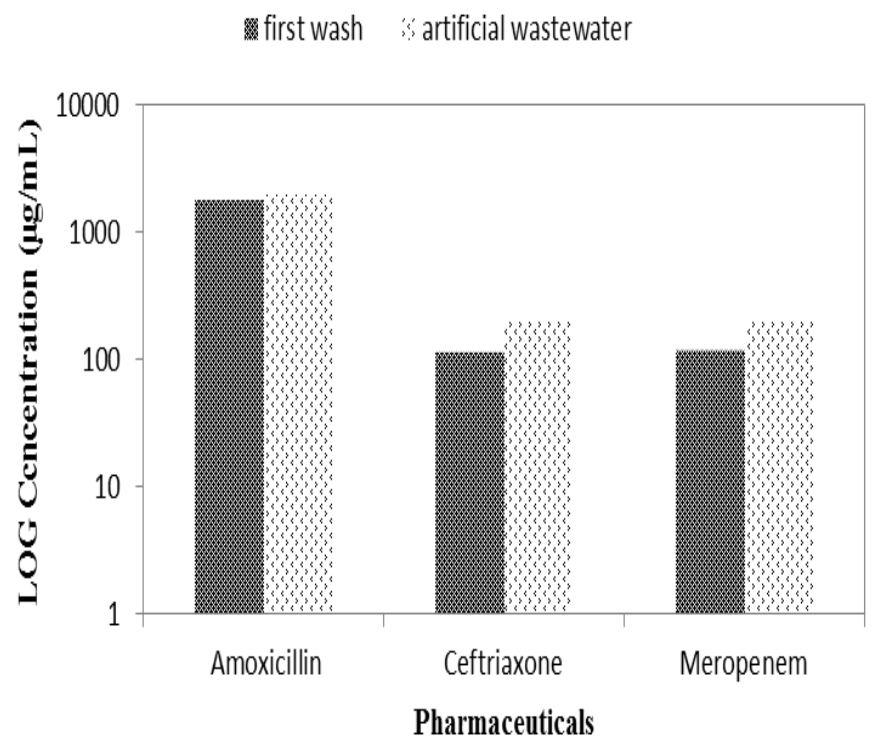

Fig. 2 Averaged concentration of first wash and artificial wastewater from typical equipment cleaning processe TABLE I

SUMMARY OF CONCENTRATION AND COD OF THE 3 ARTIFICIAL

\begin{tabular}{|c|c|c|}
\hline \multirow{2}{*}{ Active Compounds } & \multirow{2}{*}{ Category } & Concentration \\
& & $(\mu \mathrm{g} / \mathrm{L})$ \\
\hline Amoxicillin (AMO) & \multirow{3}{*}{ Antibiotic } & $2 * 10^{6}$ \\
\cline { 1 - 1 } Ceftriaxone (CEF) & & $2 * 10^{5}$ \\
\hline Meropenem (MER) & & $2 * 10^{5}$ \\
\hline
\end{tabular}

To formulate wastewater models assessing the performance of our TWHPO technology, the concentrations of our artificial wastewater samples were set at least the maximum concentrations present in the first wash if not higher (Table 1). In general the analysis of wastewater (first wash) can produce large variation in concentration levels from batch to batch of a given plant or from factory to factor (Ort et al., 2010).

In the actual production, these solvents present in the formulation have been evaporated in the granule drying or other heat-related processes such that they are no longer exist in the wastewater in the equipment cleaning process. Hence the present of these solvent is not relevant to the use of TWHPO in the actual setting in the factory. Also the residual

$\mathrm{H} 2 \mathrm{O} 2$ may exist after TWHPO will be much less than the original intended concentration. If present in the treated wastewater, it can be eliminated from the wastewater stream and converted to water and oxygen via catalytic processes.

\section{B. Degradation of pharmaceutical active ingredients by wet oxidation treatment}

At $5 \% \mathrm{H} 2 \mathrm{O} 2$ treatment, most tested active ingredients were subject to very strong oxidation condition (Fig. 3). Apparently the higher temperature setting, the faster degradation of all active ingredients. There were some active ingredients that were more recalcitrant than the others. For instance, AMO was the most resilient to oxidation in the antibiotics categories, respectively. For the AMO treatment using 5\% $\mathrm{H} 2 \mathrm{O} 2$, the temperature setting must be higher than $140{ }^{\circ} \mathrm{C}$ to achieve complete degradation within $1 \mathrm{~min}$ treatment time. These oxidation kinetic profiles of each wastewater model present a good measurement of their relative stability towards strong oxidation condition. The rest of the tested active ingredients were highly sensitive to high temperature wet oxidation.

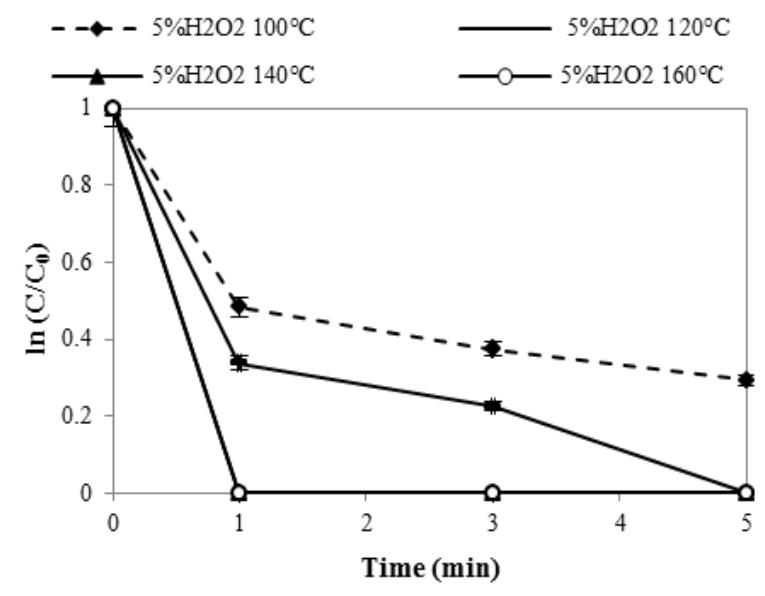

(a). Amoxicillin

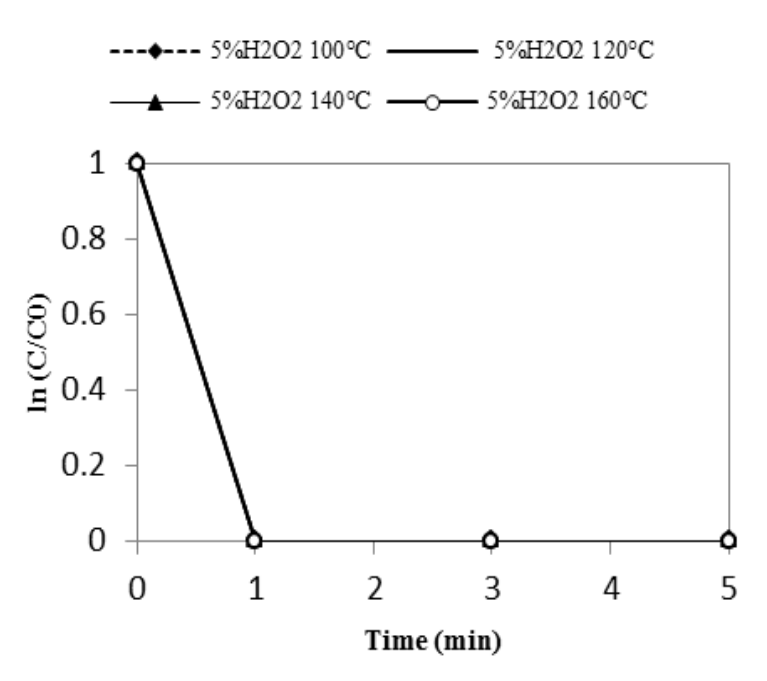

(b). Ceftriaxone 


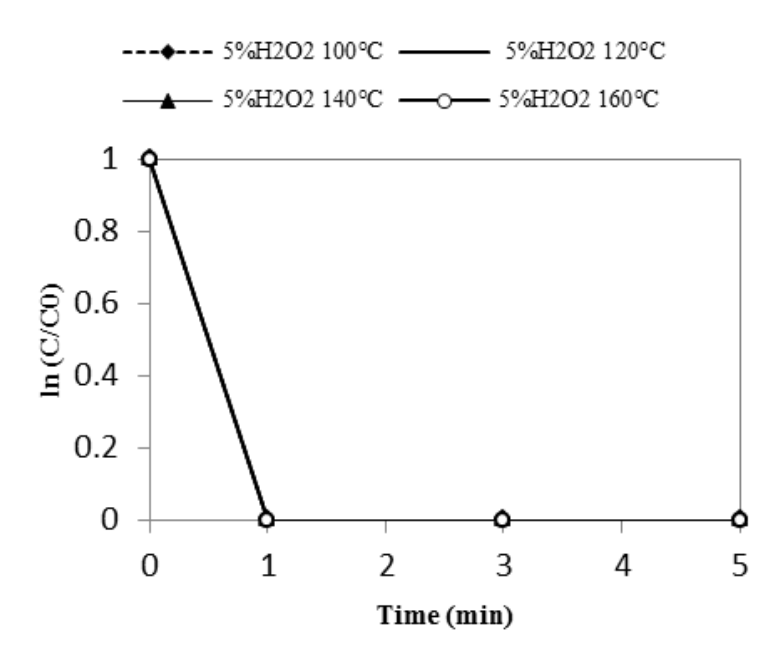

(c). Meropenem

Fig. 3 Comparison of degradation drug to AOP treatment using $5 \% \mathrm{H} 2 \mathrm{O} 2$ at different temperatures $(100,120,140$, and $160 \mathrm{oC})$

There were compounds, such as the antihypertensive metoprolol, antiepileptic carbamazepine, and the antibiotic sulfamethazine the exhibited low removal efficiencies below $30 \%$. Especially, removal of antibiotics was observed to vary between -11.2 and $69 \%$. There is data compilation of successful cases in the literature showing the use of advanced oxidation processes to remove these biorecalcitrant pharmaceuticals and PPCPs. For instance, the combined application of ozone and hydrogen peroxide was hypothesized to facilitate $\mathrm{OH}$-radical formation and produce rapid degradation for 2, 4-Dichlorobenzoic acid, Clofibric acid, Ibuprofen and Diclofenac to non-detectable by GC/MS (Zwiener et al., 1998).

\section{Proposed mechanism of elevated temperature wet oxidation on pharmaceuticals}

Similarly, higher temperature and $\mathrm{H} 2 \mathrm{O} 2$ concentration had been seen to effectively remove 3 species of cephalosporin antibiotics in equipment cleaning wastewater. Strong oxidation condition (100 oC and 5\% $\mathrm{H} 2 \mathrm{O} 2)$ enabled complete removals of ceftriaxone and cephalexin in $30 \mathrm{~min}$ and hydroxyl radicals was assumed to accelerate the fast degradation rate of antibiotic contaminants. The measurement of trace antibiotic at the end of $\mathrm{H} 2 \mathrm{O} 2$ treatment suggested the different degree of degradation recalcitrance following this order: ceftazidime>ceftriaxone>cephalexin. The underlining principle of our rapid TWHPO is hinged upon the superfluous generation of hydroxyl radicals from hydrogen peroxide substrate at high temperature. There probably are other radical species, which are highly reactive and non-selective substances, generated simultaneously as shown in (1-5) as proposed by Snell and Ettre (1971).

$$
\begin{array}{ll}
\mathrm{H}_{2} \mathrm{O}_{2} & \rightarrow 2 \cdot \mathrm{OH} \\
\mathrm{H}_{2} \mathrm{O}_{2}+\cdot \mathrm{OH} & \rightarrow \mathrm{HO}_{2} \cdot+\mathrm{H}_{2} \mathrm{O} \\
\mathrm{H}_{2} \mathrm{O}_{2}+\mathrm{HO}_{2} \cdot & \rightarrow \cdot \mathrm{OH}+\mathrm{H}_{2} \mathrm{O}+\mathrm{O}_{2} \\
2 \cdot \mathrm{OH} & \rightarrow \mathrm{H}_{2} \mathrm{O}_{2} \\
2 \mathrm{HO}_{2} \cdot & \rightarrow \mathrm{H}_{2} \mathrm{O}_{2}+\mathrm{O}_{2} \\
\cdot \mathrm{OH}+\mathrm{HO}_{2} \cdot & \rightarrow \mathrm{H}_{2} \mathrm{O}+\mathrm{O}_{2}
\end{array}
$$

and hydroxyl $(\cdot \mathrm{OH})$ where hydroxyl radical is probably the most well-known and cited having a high oxidation potential E0 $=2.8 \mathrm{~V}$ (Pera-Titus et al., 2004). Most light oxidation using UV light to photocatlyst peroxide to hydroxyl radical (Equation 1). Since we utilized dark oxidation, the elevated temperature hypothetically promotes the production of $\bullet \mathrm{OH}$ as in the similar way. Both high concentration of $\mathrm{H}_{2} \mathrm{O}_{2}$ and/or high temperatures produce higher $\bullet \mathrm{OH}$ concentration and better oxidation as seen in Fig 3. The generation of $\bullet \mathrm{OH}$ reacts with $\mathrm{H}_{2} \mathrm{O}_{2}$ to create $\mathrm{HO}_{2}$ • and more $\cdot \mathrm{OH}$ as shown in (2-3). High temperature perhaps plays an important role in moving these reactions to the right and enhancing the oxidation power. If there is no oxidizable substance in the reactor, the surplus of $\bullet \mathrm{OH}$ and $\mathrm{HO}_{2} \bullet$ radicals react with one another and $\mathrm{H}_{2} \mathrm{O}$ and $\mathrm{O}_{2}$ are created as by-products (4-6). However if there is a presence of pharmaceutical compounds, both $\bullet \mathrm{OH}$ and $\mathrm{HO}_{2} \bullet$ radicals can readily oxidize these compounds and partially to intermediate products in (2.7) or completely to $\mathrm{CO}_{2}$ and $\mathrm{H}_{2} \mathrm{O}$ (given enough time) in (2.8) (Andreozzi et al., 1999; Bolton et al., 2001; Pignatello, 1992; Zhang et al., 2010).

$$
\cdot \begin{array}{r}
\mathrm{OH}+\mathrm{EE}_{2} \\
\cdot \mathrm{OH}+\text { Intermediate }
\end{array} \rightarrow \quad \rightarrow \text { Intermediate }
$$

Apart from the reaction species noted in Equation 1-8, other possible by-products may include inorganic salts and impurity that this derivative and their conversion can mitigate oxidation reaction and produce less aggressive products. Nevertheless, high $\mathrm{H} 2 \mathrm{O} 2$, high temperature and /or longer oxidation treatment can facilitate and maintain oxidation to achieve the desirable target.

\section{CONCLUSION}

High temperatures and $\mathrm{H} 2 \mathrm{O} 2$ concentrations activated strong oxidation conditions rendering fast degradation of micro pollutants. At $140 \mathrm{oC}$ and $5 \% \mathrm{H} 2 \mathrm{O} 2$ the most resilient chemical was AMO requiring $1 \mathrm{~min}$ to achieve complete destruction whereas other active compounds were disintegrated in less than $1 \mathrm{~min}$. The use of TWHPO has shown promising results to treat biorecalcitrant pharmaceutical wastewater, like pharmaceuticals and PPCPs. The main mechanism to achieve fast mineralization was the generation of $\bullet \mathrm{OH}$. And the strong oxidizing reaction of $\bullet \mathrm{OH}$ radicals with micro pollutant present in wastewater.

\section{ACKNOWLEDGMENT}

This work was financially supported by the This work was financially supported by the Millimed Co., Ltd. and Fehalab Co., Ltd Special thanks are extended to the Thailand Research Fund, namely - research and researcher for industry: (STEM Workforce) Science, Technology, Engineering and Mathematics (Grant No. SCA-CO-2560-4939-TH).

There were two species of free radicals perhydroxyl $\left(\mathrm{HO}_{2}{ }^{\bullet}\right)$ 


\section{REFERENCES}

[1] Al-Kdasi, A., Idris, A., Saed, K., \& Guan, C. T. (2004). Treatment of textile wastewater by advanced oxidation processes - a review. Global nest: the Int. J, 6(3), 222-230.

[2] Andreozzi, R., Caprio, V., Insola, A., \& Marotta, R. (1999). Advanced oxidation processes (AOP) for water purification and recovery. Catalysis today, 53(1), 51-59. https://doi.org/10.1016/S0920-5861(99)00102-9

[3] Andreozzi, R., Canterino, M., Marotta, R., \& Paxeus, N. (2005). Antibiotic removal from wastewaters: the ozonation of amoxicillin. Journal of hazardous Materials, 122(3), 243-250. https://doi.org/10.1016/j.jhazmat.2005.03.004

[4] Andreozzi, R., Caprio, V., Marotta, R., \& Radovnikovic, A. (2003). Ozonation and $\mathrm{H} 2 \mathrm{O} 2 / \mathrm{UV}$ treatment of clofibric acid in water: a kinetic investigation. Journal of Hazardous Materials, 103(3), 233-246. https://doi.org/10.1016/j.jhazmat.2003.07.001

[5] Behera, S. K., Kim, H. W., Oh, J. E., \& Park, H. S. (2011). Occurrence and removal of antibiotics, hormones and several other pharmaceuticals in wastewater treatment plants of the largest industrial city of Korea. Science of the Total Environment, 409(20), 4351-4360. https://doi.org/10.1016/j.scitotenv.2011.07.015

[6] Boyd, G. R., Reemtsma, H., Grimm, D. A., \& Mitra, S. (2003). Pharmaceuticals and personal care products (PPCPs) in surface and treated waters of Louisiana, USA and Ontario, Canada. Science of the total Environment, 311(1-3), 135-149. https://doi.org/10.1016/S0048-9697(03)00138-4

[7] Buxton, G. V., Greenstock, C. L., Helman, W. P., \& Ross, A. B. (1988). Critical review of rate constants for reactions of hydrated electrons, hydrogen atoms and hydroxyl radicals $(\cdot \mathrm{OH} / \cdot \mathrm{O}-$ in aqueous solution. Journal of physical and chemical reference data, 17(2), 513-886. https://doi.org/10.1063/1.555805

[8] Camacho-Muñoz, D., Martín, J., Santos, J. L., Aparicio, I., \& Alonso, E. (2012). Effectiveness of conventional and low-cost wastewater treatments in the removal of pharmaceutically active compounds. Water, Air, \& Soil Pollution, 223(5), 2611-2621. https://doi.org/10.1007/s11270-011-1053-9

[9] Chatzisymeon, E., Foteinis, S., Mantzavinos, D., \& Tsoutsos, T. (2013). Life cycle assessment of advanced oxidation processes for olive mill wastewater treatment. Journal of Cleaner Production, 54, 229-234. https://doi.org/10.1016/j.jclepro.2013.05.013

[10] Deegan, A. M., Shaik, B., Nolan, K., Urell, K., Oelgemöller, M., Tobin, J., \& Morrissey, A. (2011). Treatment options for wastewater effluents from pharmaceutical companies. International Journal of Environmental Science \& Technology, 8(3), 649-666. https://doi.org/10.1007/BF03326250

[11] Deng, Y. (2009). Advanced oxidation processes (AOPs) for reduction of organic pollutants in landfill leachate: a review. International Journal of Environment and Waste Management, 4(3-4), 366-384. https://doi.org/10.1504/IJEWM.2009.027402

[12] Heberer, T. (2002). Occurrence, fate, and removal of pharmaceutical residues in the aquatic environment: a review of recent research data. Toxicology letters, 131(1-2), 5-17. https://doi.org/10.1016/S0378-4274(02)00041-3

[13] Shemer, H., Kunukcu, Y. K., \& Linden, K. G. (2006). Degradation of the pharmaceutical metronidazole via UV, Fenton and photo-Fenton processes. Chemosphere, 63(2), 269-276. https://doi.org/10.1016/j.chemosphere.2005.07.029

[14] Hirsch, R., Ternes, T., Haberer, K., \& Kratz, K. L. (1999). Occurrence of antibiotics in the aquatic environment. Science of the Total environment, 225(1-2), 109-118. https://doi.org/10.1016/S0048-9697(98)00337-4

[15] Ikehata, K., Jodeiri Naghashkar, N., \& Gamal El-Din, M. (2006). Degradation of aqueous pharmaceuticals by ozonation and advanced oxidation processes: a review. Ozone: Science and Engineering, 28(6), 353-414. https://doi.org/10.1080/01919510600985937

[16] Kadla, J. F., Chang, H. M., \& Jameel, H. (1997). The Reactions of Lignins with Hydrogen Peroxide at High Temperature. Part I. The Oxidation of Lignin Model Cornpounds. Holzforschung-International Journal of the Biology, Chemistry, Physics and Technology of Wood, 51(5), 428-434.
[17] Kümmerer, K. (2009). Antibiotics in the aquatic environment-a review-part I. Chemosphere, 75(4), 417-434. https://doi.org/10.1016/j.chemosphere.2008.11.086 https://doi.org/10.1016/j.chemosphere.2008.12.006

[18] Kümmerer, K. (2009). Antibiotics in the aquatic environment-a review-part II. Chemosphere, 75(4), 435-441. https://doi.org/10.1016/j.chemosphere.2008.12.006 https://doi.org/10.1016/j.chemosphere.2008.11.086

[19] Lamsal, R., Walsh, M. E., \& Gagnon, G. A. (2011). Comparison of advanced oxidation processes for the removal of natural organic matter. Water research, 45(10), 3263-3269. https://doi.org/10.1016/j.watres.2011.03.038

[20] Laxminarayan, R., Duse, A., Wattal, C., Zaidi, A. K., Wertheim, H. F., Sumpradit, N., ... \& Greko, C. (2013). Antibiotic resistance-the need for global solutions. The Lancet infectious diseases, 13(12), 1057-1098. https://doi.org/10.1016/S1473-3099(13)70318-9

[21] Xu, Z. E. N. G., \& Jianfu, L. J. Z. (2016). Wet hydrogen peroxide oxidation of synthetic pharmaceutical wastewater as a pretreatment method.

[22] Zhang, Z., Feng, Y., Liu, Y., Sun, Q., Gao, P., \& Ren, N. (2010). Kinetic degradation model and estrogenicity changes of EE2 (17 $\alpha$-ethinylestradiol) in aqueous solution by UV and UV/H2O2 technology. Journal of Hazardous Materials, 181(1-3), 1127-1133. https://doi.org/10.1016/j.jhazmat.2010.05.132 